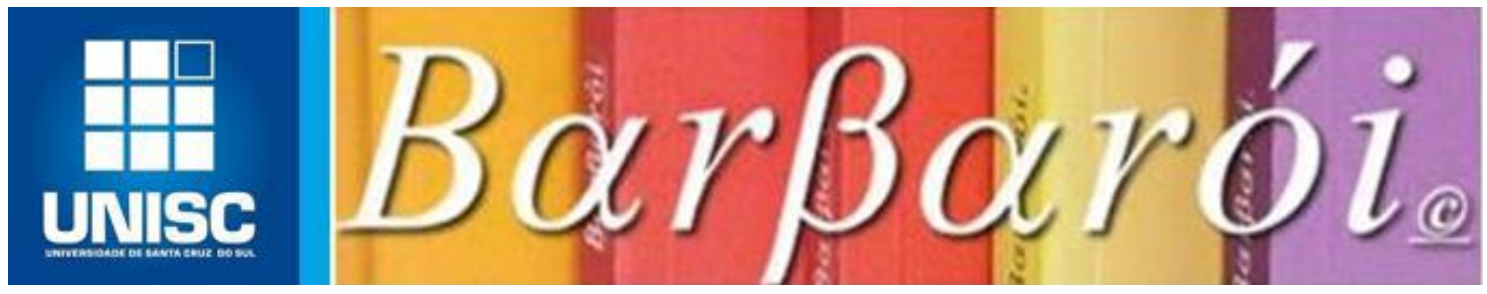

\title{
ALTA SOCIAL COMO DISPOSITIVO DE PROTEÇÃO INTEGRAL NA SAÚDE: CONTRIBUIÇÕES DO SERVIÇO SOCIAL
}

DOI: http://dx.doi.org/10.17058/barbaroi.v1i53.13716

\author{
$*$ \\ Deise Seibert \\ Universidade Federal de Santa Maria - UFSM - Brasil \\ Fernanda da Rosa Nunes Mangini \\ Universidade Federal de Santa Maria - UFSM - Brasil \\ Sheila Kocourek \\ Universidade Federal de Santa Maria - UFSM - Brasil
}

\section{Resumo}

No processo de alta social, as demandas e necessidades referentes ao processo de saúde e doença são apreendidas a partir das expressões da questão social. A alta social é tomada aqui como um dispositivo de proteção e atenção integral aos usuários, na perspectiva do SUS e, também, de ampliação e consolidação da cidadania, ela está ancorada no projeto ético-político do Serviço Social. Busca-se analisar a alta social sob um viés histórico e teórico, tendo como referência o Serviço Social de um Hospital Escola, no centro do Rio Grande do Sul, no qual constatou-se que a reinternação ocorria com frequência. Mediante a realização de um projeto de intervenção que concebe a alta social como um procedimento desenvolvido pelo Serviço Social, verificou-se resistências, sobretudo pelo modelo biomédico ainda hegemônico, que desconsidera, em parte, aspectos que compõe o cotidiano dos sujeitos.

Palavra-chave: alta social; planejamento da alta, serviço social; questão social; vulnerabilidade social.

\section{Introdução}

Hegemonicamente, o processo de alta hospitalar é realizado pela equipe médica: quando ela percebe a recuperação do paciente, assina a documentação para a saída e desocupação dos leitos hospitalares. Esse processo é tensionado pela superlotação da unidade de internação e pela administração do hospital para liberação dos leitos assim que o paciente apresente sinais de recuperação (biológica). 
A alta social, por sua vez, é um processo por meio do qual a liberação e a saída do hospital dependem da avaliação das necessidades biopsicossociais dos pacientes/usuários. Trata-se de uma iniciativa que vem sendo desenvolvida pelos Assistentes Sociais e expressa um processo de responsabilização não somente do médico, mas também da equipe multiprofissional pela saúde do usuário dentro e fora do ambiente hospitalar. A intervenção do Assistente Social é de esclarecimento, reflexão e orientação junto à equipe de saúde e ao usuário com relação às condições objetivas que incidem no processo de alta. Nesse sentido, "o profissional de Serviço Social pode ser um interlocutor entre os usuários e a equipe de saúde com relação aos determinantes sociais" (CFESS, 2010, p. 49).

O referencial da alta social está atrelado a uma concepção ampliada de saúde, bem como na integralidade do cuidado, conforme previsto na lei 8080/1990 e também na Política Nacional de Humanização (PNH). Significa exceder as questões clínicas, ou seja, o sistema de saúde precisa estar alinhado à perspectiva da escuta, entendimento e contextualização da vida do usuário, de modo a conduzir o cuidado mais adequado a sua vida e assim buscar superar o binômio adoecimento e cura. A alta social também está pautada no Código de Ética da profissão e, especialmente, nos Parâmetros para atuação do Assistente Social na área da saúde, que endossa o conceito ampliado de saúde e as necessidades de uma intervenção que capture os processos sociais e formule respostas condizentes com esses processos que sejam capazes de garantir e efetivar direitos.

O presente artigo é fruto das reflexões a partir do desenvolvimento do projeto de Estágio Curricular Supervisionado em Serviço Social, do curso de Serviço Social da Universidade Federal de Santa Maria, denominado "Alta social como forma de viabilizar o cuidado ao usuário do HUSM Internado na Clínica Cirúrgica”. O projeto de intervenção foi realizado na clínica cirúrgica do Hospital Universitário de Santa Maria, local que possui 52 leitos e atende pacientes em fase pré ou pós-operatória de clínicas diversas, entre elas, traumatologia e ortopedia, urologia, digestiva, geral, torácicas, medicina interna, vascular, cabeça e pescoço (oncologia), entre outras. O objetivo do referido projeto foi promover o fortalecimento das práticas de alta social, com vistas a garantir o acesso à rede de serviços extra e intra-hospitalar, a fim de efetivar o cuidado integral (SOUZA; SILVA; SILVA, 2013).

Este projeto emergiu a partir da observação na experiência aqui relatada. Percebeu-se que o processo de alta hospitalar ocorre, normalmente (protocolarmente), sem uma atenção da equipe multiprofissional, ou seja, sem a intervenção do Serviço Social e de outros profissionais. Ao focar somente nos aspectos clínicos, se percebe que é desconsiderada a necessidade de 
programara reorganização na rotina e no domicílio dos usuários e também, em alguns casos, de seus familiares. Ressalta-se que em alguns casos a alta hospitalar passa a ser um momento de insegurança e instabilidade, visto que será necessário lidar com limitações, incapacidades ou mesmo tratamentos longos advindos do processo de adoecimento.

Ao desconsiderar as condições objetivas e subjetivas do usuário e seus familiares, podem incidir complicações no quadro de saúde do paciente e, em última análise, produzir reinternações. Por isso, é fundamental observar as condições de recuperação fora do hospital, por exemplo, se os usuários dispõem de rede de suporte sócio-familiar, se são dependentes para o autocuidado e para realizar as tarefas diárias, se dispõem de condições financeiras para arcar com os custos de um cuidador ou instituição para cuidados. Também há que se considerar se os familiares da pessoa adoecida necessitam se afastar do trabalho para efetuar os cuidados do mesmo, fato que pode interferir nas condições socioeconômicas da família. (FLESCH; ARAUJO, 2014)

Mediante essa realidade, este artigo objetiva identificar e analisar os principais desafios para a viabilização da alta social no trabalho do Assistente Social, tendo como ponto de partida, para o debate, o desenvolvimento do projeto de intervenção relacionado à alta hospitalar. Por meio da pesquisa bibliográfica, busca-se discutir o processo de alta hospitalar do ponto de vista histórico-conceitual, situando o debate no campo da saúde coletiva e do Serviço Social.

O referencial teórico está relacionado às dimensões teórico-metodológicas e éticopolíticas do Serviço Social das últimas décadas, cujos princípios guardam conexões intrínsecas com o Projeto de Reforma Sanitária e a efetivação do Sistema Único de Saúde.

Na primeira parte deste artigo, abordamos a questão da alta hospitalar em relação às concepções e modelos de atenção à saúde. Já na próxima etapa do artigo, destacamos a concepção de alta social e sua relação com o trabalho do assistente social, mostrando a importância desse trabalho no âmbito da politica de saúde, especialmente, no âmbito hospitalar e a importância de um olhar mais social do que somente biológico. Dando sequência, destacamos o processo do projeto de intervenção realizado no Hospital Universitário de Santa Maria e seus principais desafios e conquistas no momento de sua execução.

\section{Modelos e concepções de saúde: a alta hospitalar e social}

Discutir a alta hospitalar na política de saúde implica debater os modelos de atenção à saúde e suas concepções subjacentes. Parte-se do entendimento de que determinadas 
concepções de saúde/doença, que estão atrelados a diferentes modelos de atenção à saúde, têm uma importância fundamental para compreender a alta em perspectiva histórica. A concepção de saúde como ausência de doença está fundamentada no modelo biomédico, segundo o qual a cura é o objetivo do tratamento. Portanto, a partir do momento que a doença é combatida, estão dadas as condições para a alta hospitalar. Por outro lado, a alta social está baseada numa concepção ampliada de saúde, que ultrapassa a noção de ausência de doença. Essas concepções serão expostas na sequência. (SANTOS, et. al, 2014).

Na Idade Média ocidental, o hospital era uma instituição de cunho assistencial e religioso que dava amparo aos miseráveis e enfermos. Com o avanço progressivo da ciência e da tecnologia e o desenvolvimento do capitalismo na Idade Moderna, o hospital transforma-se em local de cura, a ser organizado pelo médico, perdendo sua conotação religiosa e caritativa. A formação médica baseada no método científico positivista e no estudo da anatomia atribuía importância à observação e à experiência

\footnotetext{
das mudanças morfológicas, orgânicas e estruturais. Por conseguinte, a saúde passa a ser entendida como seu oposto lógico: a inexistência de patologia, ou seja, a própria fisiologia. Essa profunda transformação na forma de conceber a doença irá assentar as bases do sistema teórico do modelo biomédico, cuja força explicativa é responsável pela sua presença até os dias de hoje. (BATISTELLA, 2007, p. 53)
}

Sendo assim, a construção das ações de saúde foi fortemente influenciada pelo enfoque clínico do modelo biomédico, tendo o "corpo biológico" e a "doença" como principais objetos de trabalho para os profissionais de saúde. Na construção do sistema de saúde brasileiro, esse modelo foi bastante difundido pela medicina previdenciária, privada e dos grupos médicos, tendo como locus de atuação o hospital e a busca da maior especialização dos profissionais para o enfrentamento dos problemas de saúde.

O modelo biomédico que também ficou conhecido como flexeneriano, biologicista ou hospitalocêntrico está centrado na doença, no biológico e, em procedimentos, tendo o hospital como local privilegiado para combate às doenças. Esse modelo prevê que o trabalho seja desenvolvido de forma fragmentada, com predomínio de práticas hierarquizadas e desiguais entre as diferentes categorias profissionais. Uma de suas características centrais é a ênfase na especialização e no uso intensivo de tecnologias físicas. (PAGLIOSA; DA ROS, 2008).

A alta hospitalar vem sendo orientada pelo modelo biomédico, hegemônico nos serviços de saúde. Nesse modelo, a assistência está organizada com foco na identificação de sinais e de sintomas e no tratamento das doenças, consequentemente, a alta hospitalar está assentada no alívio desses sintomas e na cura da doença. Assim, a alta é concebida estritamente em função do quadro clínico do paciente, sendo uma decisão que cabe exclusivamente ao profissional 
médico, sem ou com pouca participação da equipe multiprofissional, que seria tida como periférica e secundária.

Se, por lado, a influência do modelo biomédico permanece viva a ponto de continuar orientando os processos de assistência e de alta hospitalar, por outro lado, o modelo de atenção à saúde no Brasil mudou para uma perspectiva oposta ao modelo biomédico e sua concepção reducionista de saúde. Essa mudança se dá paulatinamente, haja vista a presença contraditória do modelo biomédico, associada à inúmeros outros desafios postos ao campo das políticas públicas, e está balizada por uma concepção ampliada de saúde, que se estabeleceu a partir da VIII Conferência Nacional de Saúde, em 1986.

O conceito ampliado de saúde foi uma resposta ao contexto ditatorial e à crise dos sistemas de saúde, tradicionalmente orientados pelo modelo biomédico. Esse conceito foi articulado a partir do movimento de Reforma Sanitária, que buscava, entre suas reivindicações, uma mudança do sistema público de saúde, até então extremamente excludente. Para Bravo (2004), o projeto da Reforma Sanitária é fruto da mobilização da sociedade brasileira diante de um Estado conservador e assistencialista, reivindicando um Estado democrático, com políticas sociais, principalmente no setor saúde.

Em um contexto de redemocratização do país, foi estabelecida uma nova concepção de saúde coroada na Constituição Federal de 1988 e na Lei Orgânica de Saúde número 8080 de 1990. A concepção de saúde antes conhecida como sinônimo de "ausência de doença" passa a ser entendida de forma mais ampla, com destaque para o artigo $3^{\text {a }}$, segundo o qual:

os níveis de saúde expressam a organização social e econômica do País, tendo a saúde como determinantes e condicionantes, entre outros, a alimentação, a moradia, o saneamento básico, o meio ambiente, o trabalho, a renda, a educação, a atividade física, o transporte, o lazer e o acesso aos bens e serviços essenciais (BRASIL, 2013, p.02).

Além disso, é a partir da Constituição Federal de 1988, que a saúde passa a ser compreendida como direito do cidadão e dever do Estado a ser garantida por meio de um conjunto de políticas públicas, que foram expressas no Sistema Único de Saúde (SUS), herdeiro da concepção ampliada de saúde - que se articula aos princípios de universalidade, integralidade e equidade.

Ressalta-se que o conceito ampliado de saúde representou um grande avanço pela compreensão do indivíduo como ser histórico e social, que faz parte de uma família e de determinada cultura. Por meio desse conceito, o processo de saúde/doença é compreendido como um fenômeno próprio dos modos de convivência do homem, das condições de vida e 
trabalho dos indivíduos e grupos da população, que transcende a questão biológica (BUSS; PELLEGRINI FILHO, 2007).

A força de seus postulados procura resgatar a importância das dimensões econômica, social e política na produção da saúde e da doença nas coletividades. Contrapondo-se à concepção biomédica, baseada na primazia do conhecimento anatomopatológico e na abordagem mecanicista do corpo, cujo modelo assistencial está centrado no indivíduo, na doença, no hospital e no médico [...]. (BATISTELLA, 2007, p. 64)

O conceito ampliado de saúde, pressupõe, portanto, uma reorganização teórico-técnica e ético-política da formação e das práticas de saúde, o que demanda uma revisão de inúmeros processos de trabalho, tais como o da alta hospitalar, ainda organizada de modo tradicional.

Essas revisões foram sendo incorporadas junto a inúmeros documentos legais, no âmbito hospitalar destaca-se que a Política Nacional de Atenção Hospitalar (PNHOSP) no âmbito do Sistema Único de Saúde, Portaria no 3.390/2013, demarca como diretrizes, no Art. 6, as garantias relativas à universalidade de acesso, equidade e integralidade na atenção hospitalar, bem como à continuidade do cuidado por meio da articulação do hospital com os demais pontos de atenção da RAS e a garantia de um modelo de atenção centrado no cuidado ao usuário, de forma multiprofissional e interdisciplinar. Além disso, fica demarcado que alta hospitalar responsável pressupõe a transferência do cuidado, mediante orientação dos pacientes e familiares quanto à continuidade do tratamento, bem como, a articulação da continuidade do cuidado com os demais pontos de atenção da RAS (BRASIL, 2013).

Neste sentido, a PNHOSP vem corroborar a necessária intervenção de forma multiprofissional, interdisciplinar, intersetorial e em rede. O que em si vai ao encontro da proposta da alta social, como uma ação que requer cuidado especial e é considerada uma atividade interdisciplinar que envolve todos os profissionais que prestam assistência ao usuário, bem como os serviços que extrapolam a instituição hospitalar.

O planejamento da alta é uma atividade tanto interdisciplinar como multiprofissional, em que toda a equipe torna-se responsável por estabelecer um elo entre os usuários e os demais profissionais da rede externa. Essa atividade prima pela compreensão dos determinantes globais do processo saúde-doença, como parâmetro de um atendimento integral e resolutivo (FLESCH; ARAUJO, 2014).

\section{Da alta hospitalar à alta social: o papel do assistente social}

O Assistente Social insere-se no contexto hospitalar como profissional que articula o recorte social, intervindo junto a demais políticas públicas, além da saúde. Ele é um dos profissionais que identifica as necessidades e os determinantes sociais do processo de saúde e 
doença. Reconhece as condições objetivas em que estão inseridos os usuários, passando a interpretar junto à equipe multidisciplinar aspectos relevantes no âmbito social associados às causalidades das formas de adoecer.

Os processos de trabalho desenvolvidos pelos assistentes sociais nas equipes de saúde, no âmbito hospitalar, têm um olhar alinhado como princípio da integralidade, percebendo o usuário como um sujeito histórico, social, familiar e político, focando não somente a cura, mas também na promoção, prevenção, reabilitação, adaptação e cuidados paliativos em saúde (COSTA, 2000).

No Serviço Social, o debate acadêmico da alta social ainda é recente e conta com poucas produções, mais ligadas aos estágios e aos programas de residência multiprofissional em saúde. Essa temática também vem sendo abordada em revistas brasileiras e estrangeiras por autores portugueses, que vem divulgando algumas experiências. Mas o contexto histórico-social brasileiro e sua estruturação em termos de políticas públicas é bastante diferente, o que demanda o debate e a produção de conhecimento sobre a alta social nos planos institucional, regional e nacional, bem como, do perfil dos usuários, das dificuldades e das resistências, da cobertura da rede de suporte social, além da efetivação e da garantia de direitos.

A alta social está articulada com um olhar mais abrangente proporcionado pelos fundamentos teórico-metodológicos da área de Serviço Social para explicar e intervir na realidade a partir do desvelamento das expressões da questão social, baseado nos determinantes sociais, econômicos e culturais da saúde. Trabalhar a partir das expressões da questão social "permite ampliar as possibilidades de atuação e atribuir dignidade ao trabalho do assistente social, porque ele não trabalha com fragmentos da vida social, mas com indivíduos sociais que condensam a vida social" (IAMAMOTO, 2012, p. 53). Essa perspectiva coloca ao Assistente Social uma dupla requisição: de um lado, construir respostas para a garantia de direitos, que muitas vezes, envolvem situações emergenciais e requisitam condições materiais básicas para o tratamento e a reabilitação da saúde dos sujeitos e, de outro, desocultar as necessidades sociais que estão implícitas nesses processos e avançar para a sua satisfação.

É o fazer profissional sustentando por esse olhar que permite superar o imediatismo e a intervenção técnico-burocrática, por meio do qual se pode dar visibilidade as desigualdades e resistências sociais e construir estratégias capazes de coletivizar demandas pelo direito a ter direitos. Nesse sentido, a alta social está em consonância com o projeto ético-político da profissão, especialmente com o Código de Ética e os Parâmetros para atuação do Assistente Social na saúde, como balizas que justificam e orientam a alta na perspectiva da ampliação e 
consolidação da cidadania, mediante a garantia dos direitos civis, políticos e sociais, a democratização e facilitação do acesso de todos usuários aos bens e serviços de saúde da instituição e da rede de serviços e direitos sociais, assegurando universalidade do acesso.

A intervenção do assistente social frente a alta hospitalar é de orientação, de esclarecimento e de reflexão junto ao usuário e à equipe de saúde com relação às condições objetivas que estão impulsionando o retorno ou não para o domicílio (CFESS, 2010). Por meio da leitura das demandas e dos recursos da rede de suporte social ${ }^{1}$ do usuário, o Assistente Social analisa as potencialidades e as limitações de garantir o cuidado ao usuário no seu território, para que, desta forma, não somente o Serviço Social, mas toda a equipe interdisciplinar possa intervir de maneira adequada na realidade do usuário.

É na articulação de rede de serviços de saúde que o Assistente Social trabalha pela garantia de direitos, portanto, para o usuário que recebe alta hospitalar ou remoção e demanda outros serviços extensivos à reabilitação e à cura de suas doenças, a alta social configura-se como uma forma de garantia e de afirmação de direitos. Por meio da leitura crítica da realidade do usuário, de sua família e dos recursos disponíveis no território, é que o Assistente Social utiliza sua bagagem teórica e seus instrumentais técnico-operativos para garantir o acesso aos direitos (SOUZA, 2008).

A alta social dá-se nos casos em que usuários internados na unidade hospitalar encontram-se aptos à alta clínica hospitalar, de acordo com a equipe médica responsável, porém, durante sua internação, apresentam demandas sociais, que interferem no seu retorno ao domicílio, na continuidade do tratamento e, portanto, na reabilitação da sua saúde (LEAL; XAVIER s/d). Por vezes, tais demandas não são levadas em consideração quando do planejamento da alta hospitalar, relegando ao Serviço Social a tarefa de propor soluções rápidas e eficazes que possibilitem o retorno do sujeito ao seu cotidiano.

Nesse sentido, as redes de atenção à saúde ${ }^{2}$ vão garantir o prosseguimento do cuidado no território tanto nos aspectos sociais quanto nos de saúde no sentido de melhorar a qualidade de vida do usuário, no que diz respeito ao tratamento, reabilitação e acompanhamento (CARVALHO, 2014; MASFRET, 2012).

\footnotetext{
${ }^{1}$ Segundo Baptista (2000), as redes de apoio social subdividem-se em diferentes modalidades, quais sejam: redes sociais espontâneas, redes de serviços sociocomunitários, redes setoriais públicas, redes setoriais privadas e redes sociais movimentalistas.

2 Compreendidas como "arranjos organizativos de ações e serviços de saúde, de diferentes densidades tecnológicas, que integradas por meio de sistemas técnico, logístico e de gestão, buscam garantir a integralidade do cuidado" (BRASIL, 2010, p.01).
}

Barbarói, Santa Cruz do Sul, n.53, p.<272-290>, jan./jun. 2019 
A integralidade deve nortear as práticas dos profissionais da saúde e a organização do processo de trabalho, neste sentido o objetivo é facilitar o regresso do sujeito para a família ou a transferência adequada, e em tempo útil, para outros serviços de saúde, assegurando, em qualquer caso, a continuidade do cuidado, a garantia da qualidade do serviço prestado, evitandose a reinternação.

Por isso, a principal preocupação do assistente social é fazer coincidir a alta clínica hospitalar com a alta social, para que tenha tempo e condições de oferecer as respostas necessárias à garantia da continuidade do cuidado ao usuário, mediante a análise particularizada da realidadede cada usuário, e procurando soluções quando essa convergência não é possível, ou seja, quando o usuário recebe alta clínica hospitalar, mas não tem reunidas as condições sociais para a reintegração na família e na comunidade (CARVALHO, 2014; GUADALUPE, 2009; SACARRÃO, 2013).

O usuário pode solicitar a alta médica, tendo autonomia para decidir sobre a continuidade do seu tratamento e procedimentos a ser submetido. Segundo o código de ética médica, apenas em caso de iminente risco de vida os médicos podem se recursar a dar alta. Nesses casos, o pedido de antecipação de alta por parte do usuário pode ser decorrente de concepções culturais e religiosas, ausência de informação e conhecimento sobre o tratamento, sobretudo, da falta de condições sociais e de vida desse sujeito, como necessidade de trabalhar para sobreviver, prover o cuidado dos filhos e da família, etc, (CFESS, 2010).

O Assistente Social precisa gerir a resposta à essas situações, passando à equipe clínica o conhecimento da situação social do usuário, a fim de conseguir manter a internação hospitalar até que se reúnam as condições para o regresso ao domicílio ou a institucionalização do usuário. A colaboração da equipe médica e dos profissionais por meio do trabalho em equipe multiprofissional permite organizar e planejar a alta de forma que o Assistente Social consiga melhor articular a rede de serviços. Segundo Carvalho (2014, p. 265), “o planejamento da alta implica um processo de acolhimento, aprofundamento do diagnóstico, planeamento da intervenção, acompanhamento e avaliação integração no domicílio - meio de origem."

Outro importante papel desempenhado pelo assistente social é o contato direto com as demais instituições de saúde que compõe a rede, localizadas, sobretudo no território. Também cabe situar o cotidiano dos usuários, mapeando quem irá gerenciar o cuidado, nos casos em que ele não tenha autonomia, apoiando e encorajando a equipe familiar a se co-responsabilizar pelos cuidados continuados. 
O Assistente Social, atento aos processos de dependência de ordem econômica, biopsíquica e social que podem ser gerados pelo adoecimento, busca meios de garantir a autonomia e de anular o isolamento social do usuário (CARVALHO, 2014; DGS, 2006). De acordo com os Parâmetros para atuação do assistente social na área da saúde,

a alta médica e a alta social devem acontecer concomitantemente. Em situações em
que o usuário já tiver recebido a alta médica hospitalar sem condições de alta social,
cabe ao profissional de Serviço Social notificar à equipe, registrando no prontuário a
sua intervenção, de forma a ratificar o caráter do atendimento em equipe, com o
objetivo de estabelecer interface do usuário/familiar com a equipe. (CFESS, 2010, p.
48).

Além disso, o profissional precisa evidenciar que a alta hospitalar pode gerar diminuição dos custos ao sistema de saúde num primeiro momento, contudo a longo prazo os efeitos como a reinternação ou a piora do quadro geral de saúde do usuário elevam os custos (FLESCH, ARAUJO, 2014). Neste sentido, no registro em prontuário, o profissional informa as possíveis complicações do usuário de saúde, assim como a possibilidade do mesmo retornar ao hospital com complicações decorrentes das condições sociais do usuário (ausência ou precariedade da habitação, por exemplo).

Por fim, destaca-se que o acompanhamento da alta social poderá ocorrer a partir da referência do usuário para as instituições de saúde e/ou sociais, através da continuidade do atendimento, propiciando espaços para que o usuário acesse de forma integral a rede de serviços de saúde.

\section{A alta social no Hospital Universitário de Santa Maria/RS}

Atualmente, no Hospital Universitário de Santa Maria (HUSM), atenta para PNHOSP/2013 a qual tem como imperativo no seu Art. 11, § 4º , que o plano terapêutico será elaborado de forma conjunta pelas equipes. Quando se refere a um usuário com quadro clínico complexo ou de alta vulnerabilidade, o objetivo da equipe está ancorado em reavaliar o diagnóstico e redefinir as linhas de intervenção terapêutica, informações estas que devem ir sendo registradas em prontuário unificado compartilhado pela equipe multiprofissional. Por isso, o atendimento aos usuários da clínica cirúrgica é realizado pela equipe multiprofissional, entretanto, a decisão da alta ainda é predominantemente médica. Ou seja, prevalece o critério clínico, da saúde como ausência de doença.

Contudo é necessário desvendar a situação social do usuário e/ou sua família para garantir os cuidados continuados e a reabilitação após a saída do hospital, pois, muitas vezes,esses sujeitos não têm condições adequadas, como moradia insalubre ou até mesmo 
ausência de moradia, por exemplo. É o caso dos usuários em situação de rua que demandam uma rede de suporte institucionalizada para a sua reabilitação.

Em vista dessa realidade é que foi desenvolvido o projeto de intervenção denominado "Alta social como forma de viabilizar o cuidado ao usuário do HUSM Internado na Clínica Cirúrgica", que teve como objetivo promover a alta social a partir do acesso à rede de serviços extra e intra-hospitalar, com a finalidade de garantir o cuidado integral. Para tanto, o projeto previa o conhecimento da rede de suporte social e familiar do usuário, isto é, da composição, da dinâmica e da situação familiar, além dos equipamentos e serviços da rede extra-hospitalar. O projeto também previa a construção de um fluxo de Procedimentos Operacionais Padrão $\left(\mathrm{POP}^{\prime} \mathrm{s}^{3}\right)$ para organizar e dar visibilidade à alta social.

As principais abordagens previstas no projeto de intervenção foram executadas, preferencialmente, no leito do hospital em face das condições de saúde do usuário e da ausência de espaço físico específico. Por meio da organização e do planejamento da alta social, buscouse envolver toda a equipe, estabelecendo um elo entre os usuários e os demais profissionais da rede interna e externa. Em função da superlotação do hospital e da falta de espaço físico para reuniões, apenas os casos mais complexos foram debatidos com a equipe multiprofissional, que apresentou sugestões resolutivas para as situações apresentadas.

A aplicação das fichas de atendimento tiveram o propósito de conhecer a composição e a situação familiar do usuário, especialmente a situação trabalhista e de sua família. Logo em seguida, era realizado um checklist sobre os encaminhamentos e os procedimentos a serem realizados pelo profissional do serviço social. Os procedimentos realizados no projeto de Alta Social foram os seguintes:

\footnotetext{
Iniciar pela realização de instrumentais como fichas de atendimentos e escutas com usuários internados, com intuito de observar as expressões da questão social, assim como, conhecer a rede de apoio do usuário;

Durante o processo de internação hospitalar, acompanhar o usuário para identificar suas limitações e a superação/evolução destas;

Propor discussão de casos, sempre que necessários, nas reuniões de equipe;

Solicitar, sempre que necessária intervenção explicativa de demais profissionais, com vistas a esclarecer o usuário e ou familiar/cuidador sobre sua condição de saúde e tratamento;

- Realizar contato com a rede de serviços, necessários de serem acionados, com vistas à garantia de continuação do tratamento do usuário em ambiente domiciliar e/ou institucional, preferencialmente no território do usuário;

- $\quad$ Realizar encaminhamentos para a rede de saúde e socioassistencial.
}

\footnotetext{
${ }^{3}$ Os Procedimentos Operacionais Padrão (POPs) são documentos imprescindíveis para o exercício de qualquer tarefa realizada com qualidade, eficiência e eficácia, obedecendo critérios técnicos e observando normas e legislação das áreas pertinentes. Os POPs servem de veículo para que as informações acerca dos mais diversos processos cheguem com segurança ao executor.
}

Barbarói, Santa Cruz do Sul, n.53, p.<272-290>, jan./jun. 2019 
Em função do cronograma de execução, o projeto foi delimitado ao acompanhamento de um número de dez usuários da saúde, da clinica de traumatologia localizada no $3^{\mathrm{a}}$ andar do HUSM, na clinica cirúrgica. A maioria dos responsáveis por esses usuários eram filhos e companheiros dos internados. A situação socioeconômica dos usuários não passava dos dois mil reais mensais, para prover a subsistência das suas famílias, compostas em média por quatro à seis pessoas, havendo um caso de desemprego. Dois dos usuários se encontravam aposentados, recebendo beneficio previdenciário. Dois dos usuários se encontravam trabalhando com carteira assinada, recebendo um pouco mais de um salario mínimo. Outros dois usuários viviam de trabalhos informais e não faziam contribuição ao Instituto Nacional de Seguro Social (INSS).

Assim, havia um número significativo de usuários em situação de vulnerabilidade social, cujo modo como viviam e trabalhavam era determinante em seu processo de saúde e adoecimento. Quando hospitalizados, esses usuários apresentam dificuldades para aderir ao tratamento, o que acaba interferindo na evolução clínica destes. Desta forma é que buscamos identificar as expressões da questão social, entre os quais a situação socioeconômica, as desigualdades de gênero, etnia, raça, deficiência física, acessibilidade, que constituíssem as maiores barreiras ao acesso a direitos e aos serviços de saúde, entre outros.

As situações socioeconômicas interferiam na maneira do auto cuidado, pois a maioria dos usuários após a saída do hospital manifestava a necessidade de voltar a trabalhar. Nos casos em que não se obtinham recursos para a continuidade do tratamento - por falta de recursos na rede de apoio aos usuários de saúde, como medicamentos necessários para o tratamento através da farmácia popular, por exemplo -, observou-se que os usuáriosnão aderiam ao tratamento devido à falta de condições socioeconômicas de pagar pelo valor da medicação.

Cabe aos Assistentes Sociais acionar as redes que o usuário venha a necessitar, orientando os familiares sobre os encaminhamentos necessários e demais providências a serem tomadas para a viabilização dos seus direitos. No processo de alta, as principais redes extrahospitalares acionadas foram do território do usuário, como as Secretarias de Saúde dos municípios, hospitais e unidades básicas de saúde, com intuito de obter medicação, aplicação de injetáveis, acompanhamento especial para algumas situações, além de garantir o auxíliodoença e o Benefício de Prestação Continuada (BPC). As redes intra-hospitalares acionadas foram a farmácia hospitalar, entre outras Associações de usuários para empréstimo de insumos hospitalares, como cadeira de rodas, muletas, entre outros. 
O trabalho em equipe ainda precisa avançar, pois os médicos foram resistentes para aceitar a importância do planejamento integrado da alta clínica e social, tendo em vista a recuperação e a redução das chances de retorno do usuário ao hospital pela reincidência e agravamento da doença. Dos dez usuários acompanhados durante a aplicação do projeto, nove tiveram alta nesse período, sendo que quatro não tiveram uma alta social adequada pelo aviso de saída ser muito próximo ao da alta clínica, o que remete aos modelos e às concepções de saúde divergentes dacompreensão da alta social.

Em outras palavras:

A evolução do conceito de saúde influenciou e continua influenciando a forma como a comunidade científica incorpora o paradigma da saúde, num processo de reconstrução, tanto por força das inovações científicas, quanto dos métodos e das práticas sanitárias. "O paradigma flexneriano é coerente com o conceito de saúde como ausência de doença e constitui uma âncora que permite sustentar a prática sanitária da atenção médica" (MENDES, 1996, p.239).

Nesse ínterim, cabe reafirmar a importância que se tem de cada profissional de saúde. Nos últimos dias de execução do projeto de intervenção, os médicos começaram a procurar mais o Serviço Social para viabilizar os direitos do usuário da saúde. A procura após aplicação do projeto, teve um aumento para informar sobre a situação do usuário e o planejamento da alta social. Em que pese esses obstáculos, metade dos usuários tiveram alta com todos os seus direitos garantidos, desde previdenciários até um simples equipamento para locomoção emprestado por algum órgão. Esse resultado se deu por meio do diálogo intensivo com equipe médica, explicando a importância de uma alta planejada tendo em vista não somente o estado clinico do usuário, mas também o seu estado social.

As principais dificuldades encontradas para viabilizar a alta social foram à falta de recursos para atendimento aos usuários, principalmente na rede de suporte social, que decorre da precarização dos serviços e das condições de trabalho dos profissionais. Essas dificuldades remetem ao contexto de crise dos últimos anos, no qual o Estado orientado por princípios neoliberais corta gastos sociais,colocando as políticas sociais em uma perspectiva regressiva, isto é, com prioridade para as políticas públicas focalizadas na pobreza extrema, transferência de responsabilidades pela provisão das políticas à família e à sociedade e incentivo às parcerias público-privadas e às privatizações em detrimento dos direitos sociais historicamente conquistados.

Outra dificuldade encontrada para a viabilização da alta social foi a fragmentação e a falta de comunicação entre as instituições. A comunicação é um elemento fundamental e importante para que o trabalho em rede seja orientado e articulado. Um dos pontos cruciais da 
garantia da comunicação é a ampla divulgação dos serviços e o conhecimento da rede pelo conjunto dos profissionais. Por outro lado, a proximidade dos serviços com os usuários e sua realidade, entre os próprios equipamentos públicos que executam diferentes políticas sociais contribui para o desenvolvimento de processos de trabalho em rede.

O Assistente Social é o profissional que procura conhecer o suporte social e familiar do usuário para entender sua historicidade e intervir de uma forma eficaz, garantindo o amparo necessário ao usuário de saúde que se encontra num momento de tratamento e recuperação. Compreender a composição e a dinâmica familiar, identificar possíveis conflitos, se existem e o porquê, mediar para o fortalecimento dos vínculos familiares, após a saída do hospital, faz parte da concepção de alta social, desenvolvida pelo Assistente Social. Esse profissional vê a família numa perspectiva de totalidade, considerando os seus contínuos processos de mudanças, tanto de ordem interna como externa, como o desemprego, por exemplo.

A intervenção foi avaliada mediante análise dos números referentes à quantidade de altas sociais realizadas no período, do número de encaminhamentos para a rede e das redes mais utilizadas, bem como, das dificuldades encontradas para acioná-las. O Procedimento Operacional Padrão (POP’s), realizado para execução do projeto de intervenção, foi um instrumento que contribuiu para o planejamento da alta social, aplicado na triagem do usuário no andar, permitiu coletar o máximo de informações possíveis para acompanhar cada caso até a alta hospitalar, possibilitando acionar, de forma organizada e antecipada, os demais serviços que o usuário necessitava. O POP's auxiliou no controle da alta, por meio do registro do número de altas clínica e social.

\section{Considerações finais}

A alta social é um procedimento técnico-profissional desenvolvido pelo Assistente Social com o apoio e suporte da equipe multiprofissional e das redes de serviços públicos e comunitários. Pressupõe, portanto, uma ruptura com o modo de intervenção profissional pautado na supervalorização da doença (estritamente biológica), que tem como base o modelo biomédico. Para tanto, torna-se crucial o resgate da proposta do conceito ampliado de saúde, que abarca a compreensão dos elementos que constituem o sujeito, e, portanto percebem a saúde resultante de determinantes sociais, econômicos, culturais, étnico/ raciais, psicológicos e comportamentais.

Do ponto de vista da articulação com os direitos e as políticas públicas, a alta social está em consonância com os princípios e políticas do Sistema Único de Saúde, especialmente, com 
a concepção ampliada de saúde proposta na lei 8080/90, fruto das lutas do movimento de Reforma Sanitária. A articulação da alta social com esse marco legal lhe conecta a um projeto societário alternativo, mas que ainda tem muitos desafios para se efetivar na realidade.

A realização da alta social no cotidiano dos serviços de saúde não se faz sem contradições, como as decorrentes do sucateamento e da precarização dos serviços públicos de saúde, que podem até transformar a alta social num processo de garantia de mínimos sociais, reforçando a modalidade neoliberal de "política pobre para pobre" em detrimento dos princípios de universalidade e integralidade do SUS. É preciso atentar para as deturpações da própria concepção de "social”, que, numa acepção neoliberal, segundo Wiese (2013), vem se tornando uma categoria restrita à pobreza. Daí a importância de discutir a alta social na perspectiva da garantia de direitos, especialmente do direito à saúde.

Assim, é impossível debater a alta social sem situá-la no contexto mais amplo de precarização das políticas sociais de caráter público e universal, pois a alta depende da viabilização de um conjunto de políticas, como a política de assistência social, habitação, saneamento básico, previdência social, segurança alimentar, transporte e todos os outros que venham corroborar para a efetivação do direito à saúde do paciente. No âmbito hospitalar, o Assistente Social deve utilizar seu acúmulo teórico e leitura crítica para que a alta social aconteça na perspectiva dos direitos sociais garantidos ao cidadão como dever do Estado, sem atribuir essa responsabilidade exclusivamente à família e à sociedade.

Nesse contexto de políticas públicas restritivas, a alta social não está isenta de contradições. A superlotação do hospital e a elevação da demanda por internação pressiona a equipe médica para liberação dos leitos e para agilização da alta hospitalar. Essa situação desafia a intervenção profissional do Assistente Social que, por um lado, ao buscar garantir o direito ao cuidado à saúde de qualidade por meio da alta social, depende de condições intra hospitalares, como a permanência do usuário no leito hospitalar por mais tempo. Por outro lado, a garantia desse direito choca-se com outro direito fundamental: a busca dos usuários pela internação hospitalar, como garantia do acesso à saúde.

A alta social como procedimento profissional do Assistente Social articula uma diversidade de instrumentais como o acolhimento, a escuta sensível, a observação, as visitas domiciliares, a entrevista, os fluxos de procedimentos operacionais padrão (POP's), além de fichas de atendimento e relatórios. Esses instrumentais compõe um processo mais abrangente de investigação, planejamento, gestão e avaliação das ações, e supõe conhecimentos de vários 
aspectos da realidade social dos usuários, das instituições e das redes de suporte social, além das formas de acesso a direitos e encaminhamentos, entre outros.

Nesse sentido, as competências mobilizadas no processo de alta social precisam de reconhecimento dos gestores, da equipe e dos usuários, por meio do debate, do exercício e da visibilidade que se constrói na relação com a sociedade. Dar visibilidade ao debateda alta social permite explicitar uma dimensão ainda tímida na produção de conhecimento da área, que é seu instrumental técnico-operativo, o como fazer profissional, sobretudo, porque desvelando essa dimensão se descortina uma teleologia, o para que fazer, que orientado conforme o projeto ético-político profissional.

Por fim, aprofundar o como fazer permite adentrar nas mediações constitutivas da intervenção profissional que revelem a direção social implícita nas ações. A alta social é protagonizada pelos Assistentes Sociais e fortalecê-la na perspectiva dos direitos sociais contribui para dar visibilidade a esse trabalho que carece de legitimidade. Como afirma Netto (1996), referindo-se às transformações societárias, a profissão precisa oferecer respostas mais legitimadas e qualificadas tanto do ponto de vista técnico quanto político.

\title{
SOCIAL HIGH AS A DEVICE OF INTEGRAL PROTECTION IN HEALTH: CONTRIBUTIONS OF THE SOCIAL WORK
}

\begin{abstract}
In the process of social discharge, the demands and needs regarding the process of health and illness are apprehended from the expressions of the social question. Social standing is taken here as a protection device and integral attention to users, from the perspective of SUS and, also, of enlargement and consolidation of citizenship, it is anchored in the ethical-political project of Social Service. It seeks to analyze the social discharge under a historical and theoretical bias, having as reference the Social Service of a School Hospital, in the center of Rio Grande do Sul, where it was found that re-hospitalization occurred frequently. Through the implementation of an intervention project that conceives of social discharge as a procedure developed by the Social Service, resistance was verified, above all by the still hegemonic biomedical model, which partially disregards aspects that are part of daily life of citizens.
\end{abstract}

Keyword: social high; planning of high, social service; social issues; social vulnerability.

\section{REFERÊNCIAS}

BATISTELLA, C. Abordagens contemporâneas do conceito de saúde. In: FONSECA, A. F.; CORBO, A. M. D. (Org.). O território e o processo saúde doença. Rio de Janeiro: EPSJV/Fiocruz, 2007

BRASIL. Ministério da Saúde. Estabelece diretrizes para a organização da Rede de Atenção à Saúde no âmbito do Sistema Único de Saúde (SUS). Portaria n. 4.279, de 30 de dezembro de 2010. Disponível em: 
http://conselho.saude.gov.br/ultimas_noticias/2011/img/07_jan_portaria4279_301210.pdf Acesso: 10 de ago. 2018.

BRAVO, M.I.S. Política de Saúde no Brasil. In: BRAVO, M.I.S. et al. (Orgs.). Saúde e Serviço Social. São Paulo: Cortez; Rio de Janeiro: UERJ, 2004.

BUSS, P. M.; PELLEGRINI FILHO, A. A saúde e seus determinantes sociais.Physis, Rio de Janeiro, v.17, n.1, abr. 2007.Disponível em: $<$ http://www.scielo.br/scielo.php?script=sci_arttext\&pid=S0103$73312007000100006 \& \operatorname{lng}=\mathrm{pt} \& \mathrm{nrm}=\mathrm{iso}>$. Acesso em: 01 Dez. 2016. http://dx.doi.org/10.1590/S0103-73312007000100006.

BRASIL.Conselho Nacional de Secretários de Saúde. Assistência de Média e Alta Complexidade no SUS / Conselho Nacional de Secretários de Saúde. Brasília: CONASS, 2007

Ministério da Saúde, Lei Orgânica da Saúde no 8.080, de 19 de setembro de 1990. In: CRESS (Org). Contribuição para o Exercício Profissional de Assistentes Sociais, Coletânea de Leis. CRESS 6 ${ }^{a}$ Região, Belo Horizonte: CRESS, 2013.

Política Nacional de Atenção Hospitalar (PNHOSP) no âmbito do Sistema Único de Saúde. Portaria no 3.390, de 30 de dezembro de 2013. Disponível em: http://bvsms.saude. gov.br/bvs/saudelegis/gm/2013/prt3390_30_12_2013.html Acesso em: 10 jul. 2018.

BRITO, R. C.; KOLLER, S. H. Desenvolvimento humano e redes de apoio social e afetivo. In: CARVALHO, A. M. (Org.). O mundo social da criança: natureza e cultura em ação. São Paulo: Casa do Psicólogo, 1999.

CFESS.Conselho Federal de Serviço Social.Parâmetros para atuação de Assistentes Sociais na Politica de Saúde. Brasília: 2010.

CARVALHO, M. I. L. B. de.Política de saúde e de cuidados continuados integrados em Portugal. O planeamento da alta em Serviço Social.RevistaKatálysis, Florianópolis, v. 17, n. 2, p. 261-271, jul./dez. 2014.

COSTA, M.D.H. O trabalho nos serviços de saúde e a inserção dos assistentes sociais.Serviço Social \& Sociedade, São Paulo: Cortez, n. 62, 2000.

DGS. DirecçãoGeral da Saúde. Manual de boas práticas dos assistentes sociais da saúde na Rede Nacional de Cuidados Continuados Integrados. Lisboa: DGS, 2006.

IAMAMOTO, M. V. Projeto Profissional, espaços ocupacionais e trabalho do(a) Assistente Social na atualidade. In: CFESS. (Org). Atribuições privativas do Assistente Social: em questão. Brasília: CFESS, 2012.

GUADALUPE, S. Intervenção em Rede: Serviço Social, Sistémica e Redes de Suporte Social. Coimbra: Imprensa da Universidade de Coimbra, 2009.

FLESCH, L. D.; ARAUJO, T. C.Alta hospitalar de pacientes idosos: necessidades e desafios do cuidado contínuo. Estudos de Psicologia, v. 19, n. 3, jul./set. 2014, p. 157-238. 
MASFRET, D. C. O Serviço Social de saúde e o planeamento da alta para a continuidade de cuidados na comunidade. In: CARVALHO, M. I. L. B. de (Coord.). Serviço Social na saúde. Lisboa: Lidel; Pactor, p. 55-80, 2012.

MENDES, E. V. Uma Agenda para a Saúde.Rio de Janeiro: Hucitec, 1996.

NETTO, J. P. Transformações societárias e serviço social: notas para uma análise prospectiva da profissão no Brasil. Serviço Social \& Sociedade, São Paulo, n. 50, p. 87-132, abr. 1996.

BAPTISTA, M. V. Planejamento Social: Intencionalidade e Instrumentação. São Paulo: Veras Editora, 2000.

PAGLIOSA, F. L.; DA ROS, M. A. O Relatório Flexner: Para o Bem e Para o Mal.Revista Brasileira de Educação Médica,v. 4, n. 32,p. 492-499, 2008.

SACARRÃO, S. O Serviço Social hospitalar no interior rural: o desafio da gestão social. Interações 24, Coimbra, p. 78-85, 2013. Disponível em: www.interacoesismt.com/index.php/revista/article/download/363/378/ Acesso em: 10 jul. 2018.

SANTOS, D. de S. et al. Processo saúde/doença e estratégia de saúde da família: o olhar do usuário. Rev. Latino-Americana Enfermagem, São Paulo,v. 6, n. 22, nov./dez. p. 918-925, 2014.

SOUSA, C. T.De.A prática do assistente social: conhecimento, instrumentalidade e intervenção profissional. Revista Emancipação, Ponta Grossa, v. 1, n. 8, p. 119-132, 2008.

SOUZA, D. O.; SILVA, S. E. V.; SILVA, N. O. Determinantes sociais da saúde: reflexões a partir das raízes da "questão social”. Saúde Soc, São Paulo, v. 22, n. 1, p. 44-56, 2013.

LEAL, R. A. S; XAVIER, A. Alta hospitalar: a importância do trabalho multiprofissional e interdisciplinar em saúde. s/d. Disponível em: http://www.hu.ufsc.br/setores/servicosocial/wp-content/uploads/sites/17/2014/11/TCC-ROBERTA-SANTIN-LEAL.pdf Acesso em: 10 jul. 2018.

WIESE, M. L. A categoria social no âmbito das práticasprofissionais no ProgramaSaúde da Família do município de Blumenau.Dissertação (Mestrado em Serviço Social), Programa de Pós-graduação em Serviço Social, Universidade Federal de Santa Catarina, Florianópolis, 2013.

Data de recebimento: $24 / 06 / 2019$

Data de aceite: 19/09/2019

\section{Sobre as autoras:}

Deise Seibert Graduada em Serviço Social pela Universidade Federal de Santa Maria (UFSM). Endereço Eletrônico: deisyseibert@ hotmail.com

Fernanda da Rosa Nunes Mangini Assistente Social, mestre e doutora pela Universidade 
Federal de Santa Catarina (UFSC). Docente do Departamento de Serviço Social da Universidade Federal de Santa Maria (UFSM). Endereço Eletrônico: fernandapesquisadora@gmail.com

Sheila Kocourek Assistente Social, mestre e doutora pela Pontifícia Universidade Católica do Rio Grande do Sul (PUC-RS). Docente do Departamento de Serviço Social da Universidade Federal de Santa Maria (UFSM). Endereço Eletrônico: sheilakocourek@ gmail.com 